\title{
Development of object permanence in the New Zealand parakeet (Cyanoramphus auriceps)
}

\author{
MILDRED S. FUNK \\ Northwestern University, Evanston, Illinois
}

\begin{abstract}
Eleven young kakarikis (Cyanoramphus auriceps) were tested on 15 object-permanence tasks in a standardized scale that has been used to assess the development of human infants, some nonhuman primates, and other mammals. The birds successfully completed all tasks in this scale, and many aspects of their testing were similar to human results, such as evidencing the A-not-B error. However, the birds differed slightly but significantly from human subjects in that some of the "invisible displacements" of the later tasks were performed before the earlier visible displacement tasks. These results may relate to common ecological activities of this species. Six of the birds were parent-raised; 5 were hand-raised. The hand-raised birds achieved criteria more quickly than did the parent-raised birds possibly because the former were more accustomed to the investigator and less distractible in the test situation.
\end{abstract}

Piaget believed that object permanence--the understanding that objects continue to exist when they are not in sight-is a fundamental ability, essential to further cognitive development. He described a gradual stage-like development of this concept during the first 2 years of life, the sensorimotor period. Investigators (Harris, 1983; Mandler, 1990; Meltzoff, Kuhl, \& Moore, 1991) have questioned Piaget's timetable of the emerging abilities and whether the abilities develop in stage-like fashion, but they have not questioned the importance of the object concept to a developing organism. The manner of objectpermanence acquisition remains an active area of research.

According to Piaget $(1953,1954)$, in the first two stages, human infants can be interested in objects that move, but when an object disappears from view, they do not apparently miss the object or search for it. By the 4th month (Stage 3), infants may visually (but not manually) search for an object that has disappeared from view (Baillargeon, 1987). Later in this stage, infants can retrieve an object that is partially covered but will ignore an object seen being completely hidden under a cover. By the end of the lst year children can find an object they see being completely hidden under a cover (Stage 4), but movement of the object puzzles them. If they see an object that they have repeatedly found in one location (A) hidden in another place (B), they search in the previously rewarded location, thus making the "A-not-B" error.

This paper reports portions of research done by M.S.F. for her doctoral dissertation submitted to Northwestern University in Evanston, IL. The author thanks Irene Pepperberg and Donald Sade for their helpful suggestions and for permitting housing of research subjects in bird lab space; Rana Matteson for her interest and comments on the project; and Lois Sears for assisting in testing the birds and for filming their progress. The author also thanks William Timberlake and two unknown reviewers for their comments on earlier drafts of the manuscript. Correspondence should be addressed to M. S. Funk, Department of Biology, Roosevelt University, 430 South Michigan Ave., Chicago, IL 60605.
In the first half of the 2 nd year, children can search for an object they see moved in a sequential visible search (Stage 5), but now they are confused by "invisible displacements" (e.g., when an object is seen hidden inside a container and then the container is moved under one or more covers where the object is surreptitiously displaced so that the subjects cannot see the transfer of the object). Piaget thought children could infer an object's movements (Stage 6) only in the last half of the 2 nd year.

Object permanence (OP), an important milestone in human development, is also an important topic to explore in non-human animals because of the potential ecological advantages of OP in the lives of many species (Dumas, 1992; Etienne, 1984). Piagetian procedures are effective in cross-species comparisons because the methodology involves very detailed observations (similar to ethological procedure), and the target activities can be done by nonverbal, action-oriented subjects. Etienne (1984) viewed $\mathrm{OP}$ as an important cognitive indicator of species-specific ways of interacting with objects in the environment. Other investigators have suggested that $O P$ testing may also reveal individual differences as a function of experience/ background (Pepperberg \& Funk, 1990). The present study examined OP development in an altricial species, the New Zealand parakeet (Cyanoramphus auriceps), looking at how background-both the individual's and the species' ecology - might affect performance.

The earliest animal study to explore a Piagetian problem was that of Gruber, Girgus, and Banuazizi (1971), a longitudinal study on cats that tested OP through Stage 4. These investigators found a gradual developmental sequence in cats similar to that in humans, though Dumas and Dore (1989) found that the 4th and 5th stages were combined. There are also conflicting opinions on Stage 6 results. Dumas (1992) and Triana and Pasnak (1981) have reported data showing that adult cats reached Stage 6 . However, other investigators (Dore, 1986, 1990; Dumas \& Dore, 1989, 1991; Goulet, Dore, \& Rousseau, 1994; 
Pasnak, Kurkjian, \& Triana, 1988) did not find Stage 6 ability in adult cats. In a cross-sectional study, Gagnon and Dore (1994) tested puppies and found similarity in sequence to that in cats and early Stage 6 ability at around the lst year. Puppies and kittens did not make the A-not-B error. However, adult dogs' level of success in invisible displacements is much lower than in visible displacement tests (Gagnon \& Dore, 1992, 1993).

Many nonhuman animal studies have shown how OP develops in primate species, but some investigators have assessed only Stages 5 and 6. Chimpanzees (Pan troglodytes; see Hallock \& Worobey, 1984; Mathieu \& Bergeron, 1981; Wood, Moriarty, Gardner, \& Gardner, 1980) and gorillas (Gorilla gorilla; see Natale \& Antinucci, 1989; Redshaw, 1978; Spinozzi \& Natale, 1989) have attained full OP, though not all in the same sequence as that in human infants (see General Discussion section). In monkeys, a stumptailed macaque ( $M$. arctoides; see Parker, 1977) followed the human sequence and did early Stage 6 tasks, but there are conflicting results on capuchins (Cebus apella). Schino, Spinozzi, and Berlinguer (1990) found Stage 6 ability; however, Natale and Antinucci (1989) and Dumas and Brunet (1994) did not. One longitudinal study on rhesus (Wise, Wise, \& Zimmerman, 1974) found full OP in subjects, but a more recent study (de Blois \& Novak, 1994) questioned rhesus Stage 6 ability. Japanese macaques ( $M$. fuscata) and crab-eating macaques (M. fascicularis) reached Stage 5 following the human sequence (Natale \& Antinucci, 1989; Poti, 1989; Schino et al., 1990).

The present study is the first to track the development of OP longitudinally in an avian species. Four psittacine species (all adult birds) in laboratory testing have demonstrated full OP, and many species in the wild have shown searching skills suggesting OP (Etienne, 1984; Pepperberg \& Funk, 1990; Pepperberg \& Kozak, 1986), although young domestic chickens' searching abilities were found to be more limited (Etienne, 1973). Dumas and Wilkie (1995) tested ring doves (Streptopelia risoria) on OP tasks and found that their subjects could successfully find a reward hidden behind one of two screens, provided the birds started to search before the reward disappeared behind a screen.

Parrots, like other birds, have a well-developed visual ability; parrots also have a grasping ability that can make them very manipulatory and exploratory subjects. Members of the genus Cyanoramphus are acute observers of their environment, with a good memory of their surroundings (Nixon, 1982); they are generalists in diet and habitat (Taylor, 1985). Parker and Gibson (1977) suggest that species that have the most varied habitats and search for a broad diet are also more flexible and investigative when they are in captivity. The parakeets in this study were active and attentive subjects, gradually completing all the tasks on a standardized Piagetian scale, though not in the same order that human infants have followed.

The variety of testing procedures and the training evident in some of the animal studies make cross-species comparisons difficult. Many researchers (e.g., Parker,
1977) have designed their own tasks that resemble $\mathrm{Pi}$ aget's descriptions of common developmental activities. Others have mixed Piagetian tasks with common psychological tests, such as the Wisconsin General Test Apparatus (Vaughter, Smotherman, \& Ordry, 1972), using numerous testing and pretraining sessions that may instill a behavior that should be spontaneously performed if the subject does have the conceptual understanding in question. Still other researchers have used Uzgiris and Hunt's (1975) Ordinal Scales of Psychological Development (hereafter referred to as the $U \& H$ scales). These six scales are based on Piagetian activities that increase in difficulty through six stages, and they have been widely used in theoretical and clinical work to test young children.

Use of standardized scales eliminates scattered or ambiguous data that may result from individual-designed experiments (Wood et al., 1980), thus promoting clearer comparative cross-species assessments. Because the U\&H scales are partitioned into within-stage levels, finer distinctions may be made concerning the timing of the development of particular skills. Results on these tests are from easily observed behaviors, helpful in cross-species testing. For these reasons, tasks from the U\&H scales were adapted for use with the kakarikis.

The present study had five objectives: (1) to assess the ability of New Zealand parakeets to solve OP problems, (2) to compare their ordinality with that of human subjects, (3) to see if OP was present at fledging or whether it developed gradually, as with human infants, (4) to compare rearing effects on task performance between handraised and parent-raised parakeets, and (5) to see if their successes or failures on tasks could be related to their natural history.

\section{METHOD}

\section{Subjects}

Eleven birds were tested on 15 object tracking and searching tasks and 5 control tasks over a period of 6 months. The subject species was the golden-crowned parakeet of New Zealand ( $C$ yanoramphus auriceps), more commonly called the "kakariki" (or "little parrot"). Of the 11 young kakarikis tested, 6 were parent-reared (Group 1) in a laboratory at Northwestern University, and 5 others (Group 2)-from a later brood of the same parents-were removed from the parents when the chicks were $2-4$ weeks of age and were partly hand-reared (on schedule) and partly fed (on demand) by an unrelated pet female kakariki. Group 1 was out of the nest box around 6 weeks, and testing began then. They were in the same room as their parents but were caged separately. Group 2 , out of the nest box for feedings, began testing when their eyes were reliably opened at 4 weeks. The kakariki diet consisted of mixed parakeet and parrot seeds, water with vitamin supplement, fruits, and vegetables.

\section{Testing Environment and Search Items}

The two groups were treated as much alike as possible in caging $(30 \times 30 \times 14$ in. and $24 \times 20 \times 15$ in.), lighting, food, and testing, although in Tasks $3-15$, Group 1 had to be tested in a cage in an adjoining room because of space limitations in the laboratory, whereas Group 2 could be tested in a cage on a table $8 \mathrm{ft}$ from their siblings because they were in a much larger room. For Tasks 3 and 4 , both groups were tested atop the cage of a quiet unrelated female kakariki or in a cage nearby. For Tasks 1 and 2, the birds were assessed in the home cage. These arrangements were made because 
the fledglings would not spontaneously react to tests if isolated at this early stage.

Search objects were food items: safflower or sunflower seeds, millet, peanuts, red chili peppers, pieces of apple or grapes, carrots, or crackers. Food rewards were the only items that would motivate the young birds to search (see Triana \& Pasnak, 1981, for discussion of food rewards). Red yarn, a black pencil, a syringe with formula, and some silver keys were used in the trajectory tasks (Tasks 1 and 2). Pieces of (crumpled) blue napkins served as covers for the hidden objects (but see Task 9 below). The container for the reward in Tasks 10-12 was either a small square coffee-measuring cup or a white plastic candy cup, both of which could be covered with two fingers for the hiding procedures. In Tasks $13-15$, the investigator's hand was used.

\section{Tasks}

Tasks were from Uzgiris and Hunt's (1975) Scale I: The Development of Visual Pursuit and the Permanence of Objects (see Table 1). Tasks 1 and 2 (Stages 2 and 3, respectively) tested (1) visual tracking of an object moving in a $180^{\circ}$ arc and then (2) noting the disappearance of the object as it drops from sight. While the subject was in its home cage, its attention was drawn to a piece of red yarn (or a black pencil or silver keys) being moved in a $180^{\circ}$ arc to be tracked through the complete trajectory ( 3 trials). The subjects in Group 2 were tested for this with their feeding syringe while they were being hand fed. They were also retested on the same task 1 week later (using yarn, etc.) when they were out of the nest box in their cage.

In Task 2 ( 3 trials), the object in trajectory "disappears" at the end, and the subject should "linger with a glance at the point of disappearance." In Task 3 (Stage 3), a piece of grape or apple or millet spray was placed in front of the subject, who was atop a cage; the food was then partially covered with a blue napkin piece to test whether the bird would uncover the object in retrieving it ( 3 trials). The fruit to be retrieved was seen being completely hidden under a single cover in Task 4 ( 3 trials; Stage 4). In Task 5 (Stage 5), the subject was twice presented with seeds or a bit of fruit being com-

Table 1

Object-Permanence Scale I: Development of Visual Pursuit and Permanence of Objects (From Uzgiris \& Hunt, 1975)

\begin{tabular}{|c|c|}
\hline Task & Task Description \\
\hline 1 & Following a slowly moving object through a $180^{\circ}$ arc (3-4) \\
\hline 2 & Noticing the disappearance of a slowly moving object $(3-4)$ \\
\hline 3 & Finding an object which is partially covered (3) \\
\hline 4 & Finding an object which is completely covered (3) \\
\hline 5 & Finding an object completely covered in two places (2) \\
\hline 6 & $\begin{array}{l}\text { Finding an object completely covered in two places alter- } \\
\text { nately }(3-5)\end{array}$ \\
\hline 7 & Finding an object completely covered in three places $(5-7)$ \\
\hline 8 & Finding an object after successive visible displacements (3) \\
\hline 9 & Finding an object under three superimposed screens $(2-3)$ \\
\hline 10 & Finding an object following one invisible displacement (3) \\
\hline 11 & $\begin{array}{l}\text { Finding an object following one invisible displacement } \\
\text { with two screens ( } 2 \text { ) }\end{array}$ \\
\hline 12 & $\begin{array}{l}\text { Finding an object following one invisible displacement } \\
\text { with two screens alternated ( } 3 \text { ) }\end{array}$ \\
\hline 13 & $\begin{array}{l}\text { Finding an object following one invisible displacement } \\
\text { with three screens }(5-7)\end{array}$ \\
\hline 14 & $\begin{array}{l}\text { Finding an object following a series of invisible displace- } \\
\text { ments (4-6) }\end{array}$ \\
\hline 15 & $\begin{array}{l}\text { Finding objects following a series of invisible displace- } \\
\text { ments by searching in reverse order of hiding ( } 2 \text { ) }\end{array}$ \\
\hline
\end{tabular}

Note-Numbers in parentheses refer to trials. Scale is abbreviated from Assessment in Infancy: Ordinal Scales of Psychological Development, by I. Uzgiris and J. M. Hunt, 1975, Champaign: University of Illinois Press. Copyright 1975 by the Board of Trustees of the University of Illinois. Adapted with permission of the University of Illnois Press. pletely hidden under one of two covers ( 2 trials). In Task 6 (also Stage 5 and presented along with Task 5 ), the subject was presented with seeds or a peanut being hidden under each of two covers alternately for at least 3 trials. In Tasks 7-9, the seeds or chili pepper were hidden under one of three covers ( 5 trials), then visibly moved between the three covers ( 3 trials) and, finally, hidden under three superimposed covers ( 2 trials). Paper-plate pieces were introduced as covers to increase the search time in Task 9, and, in the 3rd session, the plates - in conjunction with a small candy cup - were used to further increase difficulty. In Tasks 7,8 , and 13-15, the three screens were placed inside the cage in early sessions and outside the cage (where they could be easily reached) in later sessions to maintain interest in the tasks.

Tasks 10-15 were Stage 6 tasks, involving invisibly displaced items whose locations were to be inferred by the subject, who did not see the objects themselves being hidden. In Task 10 (3 trials), seeds were seen to be hidden in a container; the container was then moved under a cover while the seeds were deposited there, though the deposit was not seen being done. The empty container could be shown to the subject, who should infer that a transfer of the item had taken place. Tasks 11 ( 2 trials), 12 ( 3 trials), and 13 (5 trials) were similar to Tasks 5,6, and 7, except that the rewards (seeds, cracker pieces, or a peanut) were invisibly displaced. The empty implementing carrier was placed equidistant between the covers. Task 14 (4 trials) was similar to Task 8, except that the subject saw the reward only at the outset in Task 14 when it was hidden in the investigator's hand and then moved between three covers, and the item was surreptitiously displaced under the last cover. Task 15 (presented immediately after Task 14; 2 trials) was a trick. The hiding procedure was similar to that of Task 14, but the object was left under the first cover (or withdrawn at the end) though the hand was seen to continue moving between the covers and was shown to be empty at the end. Any subject using odor as a cue would correctly retrieve the reward at the first cover. The subjects not using odor cues followed the same searching procedure as in Task 14 .

Uzgiris and Hunt believe that a systematic search of the three covers (searching backward from the last cover visited by the object to the second and the first) by the tricked subject indicates full OP involving representation of the object. Because this type of search has been rarely observed, some have questioned its usefulness (Corrigan, 1981; Fischer \& Jennings, 1981).

\section{Procedure}

Sessions were held every other day, and they lasted $20-40 \mathrm{~min}$, depending upon the attention span of the subjects. Usually only two or three tasks could be completed in a session. Two investigators assessed the subjects, one serving as observer and one as examiner.

Three correct sessions were required for each task to rule out chance performance (see Scoring Criteria section). However, the first successful session on a task was taken as evidence of its attainment (as in Uzgiris \& Hunt's study), an attempt to ascertain critical abilities as soon as they were displayed, which is essential in a developmental study. Uzgiris (1987) writes:

A step was judged as attained whenever adequate evidence ... was first obtained, except when such evidence could not be again elicited in the following session; in that case, the step was judged as attained when appropriate evidence was attained a second time. (p. 145)

Tasks were administered in scale order except when a task could not be satisfactorily done by the subjects. If subjects did not react to a new task, a familiar task was presented. If the subject did not react to the familiar task, it was assumed that there was a lack of motivation to continue testing, and the session was discontinued. If the subject reacted to the familiar task, then a more advanced task was presented. If the subject ignored that task, the reaction was noted as a "no search." If the subject responded incorrectly, it was noted as an error. If the subject performed it correctly, the task was presented the required number of times. It was presented again in 
the following test days until it was completed in 2 more sessions. The previously ignored task was also offered in those sessions. If the latter was still not performed, the tasks following the advanced task were offered in scale order. Probes ahead were helpful in ascertaining when the cognitive abilities first appeared. Success on a later task can also show that the subject is not learning to do the tasks (step by step). Tasks were administered informally to an adult kakariki to ensure that the tasks could be done and to observe performance.

Especially in the early U\&H tasks, investigators need to be aware that there are many abilities that are a part of task readiness: motor abilities, motivation, good spatial memory, adequate attention span, and sufficient socialization to respond in the test situation (see Pepperberg \& Funk, 1990). A lack of task readiness must not be confused with a subject's lack of comprehension of task demands.

Several precautions were taken to avoid training the subjects with the repeated trials (Cornell, 1978). Short sessions spaced every other day and the variety of tasks and rewards and probes ahead helped avoid training specific behaviors. Also, the examiner did not lift covers once they were placed, thus showing the subject the reward. If the subject chose incorrectly, the reward was removed still covered so that the subject would not repeatedly see cover and reward associated. Covers were moved and rearranged between trials, and hidings were not approached from the same direction in all trials so that the subject had to pay close attention and not merely go to the same location for a reward. Multiple covers were all touched to adjust them after the hide; the subject did not then learn to choose the last cover visited by the investigator's hand.

Also, precautions were taken to avoid cuing by suggestive movements or allowing odor to influence the subject's choice. After presenting a task, the investigator left the room and watched from behind a glass window in the door to the next room or from behind a tall, slatted screen. The person helping judge the performances and film some trials remained behind the camera at filming distance from the subjects. Mostly, the subjects ignored the investigators and were more likely to perform with the principal investigator absent (see also Fragaszy \& Visalberghi, 1989). Odor does not seem to be an important cue for all avian species (Healy \& Guilford, 1990; Stettner \& Matyniak, 1968). Food odors were present in all the covers; hulls and bits of food were scattered about the test area. The subjects' repeated sessions on difficult tasks (see Table 2) suggest that olfactory cues did not inform their choices (see Triana \& Pasnak, 1981, discussion of cuing). Task 15 also tested for odor.

Finally, five control tests, similar to those used by Tinklepaugh $(1928,1932)$, were presented in the month after the other tests. Control Test 1: To test memory, preferred and less preferred items

Table 2

Number of Sessions to Complete Object-Permanence Scale

\begin{tabular}{rrrrrrrrrrrrrrrrr}
\hline & \multicolumn{110}{c}{ Bird } & 1 & 2 & 3 & 4 & 5 & 6 & 7 & 8 & 9 & 10 & 11 & 12 & 13 & 14 & 15 & Total \\
\hline 1 & 3 & 3 & 3 & 3 & 3 & 9 & 7 & 6 & 3 & 3 & 6 & 4 & 5 & 3 & 3 & 64 \\
2 & 3 & 3 & 3 & 3 & 3 & 12 & 12 & 6 & 3 & 3 & 4 & 3 & 6 & 3 & 3 & 70 \\
3 & 3 & 3 & 3 & 3 & 3 & 6 & 4 & 4 & 3 & 3 & 3 & 3 & 10 & 4 & 3 & 58 \\
4 & 3 & 3 & 3 & 3 & 3 & 5 & 11 & 5 & 3 & 3 & 5 & 3 & 6 & 3 & 3 & 62 \\
5 & 3 & 3 & 3 & 3 & 3 & 10 & 5 & 4 & 3 & 3 & 3 & 7 & 4 & 4 & 3 & 61 \\
6 & 3 & 3 & 3 & 3 & 3 & 4 & 5 & 5 & 3 & 3 & 3 & 4 & 5 & 3 & 3 & 53 \\
7 & 3 & 3 & 3 & 3 & 4 & 5 & 4 & 6 & 3 & 3 & 4 & 3 & 6 & 4 & 3 & 57 \\
8 & 3 & 3 & 3 & 3 & 4 & 3 & 4 & 4 & 3 & 3 & 4 & 5 & 3 & 4 & 3 & 52 \\
9 & 3 & 3 & 3 & 3 & 4 & 7 & 8 & 4 & 3 & 3 & 4 & 6 & 3 & 3 & 4 & 61 \\
10 & 3 & 3 & 3 & 3 & 3 & 4 & 6 & 3 & 3 & 3 & 4 & 7 & 3 & 3 & 3 & 54 \\
11 & 3 & 3 & 3 & 3 & 3 & 6 & 4 & 5 & 3 & 3 & 4 & 4 & 3 & 3 & 3 & 53 \\
\hline
\end{tabular}

Note-Birds 1-6 were in Group 1 (parent-reared); Birds 7-11 were in Group 2 (hand-reared). The minimum number of sessions required to complete each task was 3 . Therefore, the minimum number of sessions required to complete the object-permanence scale was 45 . were shown the birds and hidden in one of two alternating sites. Control Tests 2 and 3: In two tests for olfaction, a preferred seed was surreptitiously hidden under one cover, and other seeds were seen being placed under another cover. Next, seeds were hidden under one of two towels, without showing the birds the hidings. Control Test 4: Testing for location versus cover, a reward was placed under one of two covers, then a paper-plate piece was placed over that cover, and the latter was removed so that the subjects chose between a cover like the one under which they had seen seeds hidden and a paper-plate piece in the location under which they saw seeds hidden. Control Test 5: The assistant presented 3 trials from Task 6 to test for presence of cues from the other investigator.

\section{Scoring Criteria}

A correct trial was one that was performed as indicated by the U\&H scales within 1 min of placement. The subjects could have no more than 1 incorrect trial in no more than 2 of the 3 sessions on each task as in previous studies (Pepperberg \& Funk, 1990; Pepperberg \& Kozak, 1986; Wood et al., 1980). Correct trials needed to be performed consecutively three to five times, as specified by the scale (see Tasks section). Other reactions (mistrials) of the subjects were (1) ignoring the hiding procedure and hidden object during the allotted search time (no search) or (2) playing with covers. Failure to repeat a task the required number of times was recorded as an "incomplete." Many trials were videotaped and were scored later by the investigators. Interobserver agreement on all scoring results was nearly perfect $(99 \%)$.

\section{RESULTS AND DISCUSSION}

All 11 birds successfully completed the 15 tasks in this scale, thus meeting criteria for full Stage 6 OP. However, the order of tasks performed by the birds was different from human subjects' ordinality. For the avian subjects, early Stage 6 invisible displacements preceded Stage 5 visible displacements with multiple covers. Aside from this surprising finding, there were many similar aspects of developing OP skills in the human and avian subjects: (1) OP was a slowly developing ability for the altricial birds, as it has been for human infants, both species showing gradual improvement in trajectory skills and growth in object concept as well as in attention necessary for the more difficult tasks. (2) Movement of the reward between covers was a problem for the young birds, as it was for human infants (see Fischer \& Bidell, 1991; Wellman, Cross, \& Bartsch, 1986). (3) Young avian subjects showed perseverative searches at previously rewarded locations (the A-not-B error), as young human and nonhuman subjects do (except for dogs and cats); however, an adult kakariki in this study and other adult birds (Pepperberg $\&$ Funk, 1990) as well as adult humans do not generally make A-not-B errors. (4) The subjects demonstrated some level of intention in their responses, as Diamond (1985) suggested for human infants, with the kakarikis positioning themselves in front of correct locations on some trials or searching for preferred seeds or climbing around the cage to come down near the rewarded location.

\section{Reactions to Tasks}

Task 1. The trajectory was a skill that slowly developed between $4 \frac{1}{2}$ and 7 weeks. Group 1 could not be tested until they left the nest box at 5-6 weeks, and then they 
were afraid of the investigator and would become immobile or return to the nest box when she approached. In early testing, they seemed not to notice the red yarn moving slowly around them in the cage, or they might notice an object but not follow its trajectory. The hungriest hand-fed subject (though not the others) did follow a trajectory of the syringe as he was being fed at $4 \frac{1}{2}$ weeks, but he did not watch the trajectory of any other object until 1 week later. Most began to show interest in objects and their movements around $5 \frac{1}{2}$ weeks; by 7 or 8 weeks, incomplete or jerky trajectories were replaced by smooth head movements.

Task 2. None of the birds was able to note the disappearance of a slowly moving object (yarn) when they began watching its trajectory. Some completed the 3rd trajectory session of Task 1 before they began to glance at the "point of disappearance," as required in the task. The two activities were performed 1 week apart by Group 1 subjects and 2 weeks apart for Group 2 subjects, who had been earlier by 1 week on Task 1 .

Task 3. There were more mistrials on Task 3 than on any other task. Group 1 subjects were tested in a room adjoining the other birds, and their mistrials may have been due to this context, the absence of their parents and sibs. Group 2 was more accustomed to the investigator and to being taken from the cage and being apart from siblings for short periods; they had fewer mistrials. For most subjects, beginning sessions were either incomplete numbers of recovery (7) of the partly covered grape (or millet) or else the item was not noted ( 8 reactions) as the subject walked past it. Because recoveries of hidden objects were quickly done by an adult kakariki, instances of not recognizing the reward by the fledglings were thought to be indications of developmental inability (perhaps they were too young to have the concept), and so these instances were not counted as errors.

Task 4. Many subjects had an early session of ignoring the covered item or losing interest when the reward was completely covered (7) or else they performed an incomplete number of recoveries (8) on Task 4 . The subjects would ignore and go past an item they saw being completely covered and then immediately uncover a nearby partly covered item (Task 3 ) and eat it. For both groups, this was the first task for which they were caged to be tested, and this caused both some delays. Most subjects were successful 2 or 3 weeks after Task 3 criterion was met.

Most subjects performed Tasks 4 and 5 in some of the same sessions. Group 2 subjects were younger than Group 1 subjects on both tasks; several Group 2 subjects made 2 errors in 1 session of Task 5 (the first A-not-B errors).

Tasks 5 and 6. Tasks 5 and 6 were presented together. Faced with repeated alternating of the reward after having found it in the $\mathrm{A}$ location for 3 or more trials, the birds tended to choose the previously rewarded location (A), thus making the A-not-B error. There were many such errors in Task 6 resulting in extra sessions (Table 2); later tasks (7-9) were then tried. There was only one such error by the adult kakariki tested on Task 6 .
Mistrials did not increase; there were none on Task 5 and only 1 on Task 6 . Only 3 subjects completed Task 6 earlier than Task 9. Task 6 achievement was delayed for both groups until after Task 9 ; for many subjects, it was delayed until after Task 10, the first of the Stage 6 tasks. A comparison of task order for birds versus humans is shown in Table 3.

Task 7. Task 7 was the most difficult task for all the birds. There were three possible hiding places, and the reward was seen placed in different locations in the 5 requisite trials. None of the birds had a successful 1st session on the task; many made errors, and several refused to search. Some subjects began on this task much earlier (by 1 month) than did others, but most subjects in both groups were performing successful searches near the same time (the end of the 6th month), suggesting a role for maturation in this ability.

Task 8. Movement of the reward between the three locations made this task difficult for the birds, though none had over 6 sessions on this task, and there was only 1 mistrial. (Except for the 5 mistrials of 2 uncooperative subjects [Subjects 3 and 7], there were only 4 mistrials for the rest of the birds on the remaining 7 tasks.) The two groups were again close on criterion times, having done Task 8 only 1 or 2 weeks after Task 7 .

In the tasks with multiple covers, the birds would often climb up and around the cage and come down close to the correct cover instead of walking past the other covers that were not concealing the reward. Possibly, they were trying to avoid the unrewarded covers, thus evincing some motivation and intention.

Task 9. Although there was an initial hesitation when they saw novel items (quarters of small paper plates used as the superimposed covers), the birds retrieved the rewards in several different fashions: reaching under the plates at first to retrieve a seed or two before pushing off

Table 3

Order in Which Human and Avian Subjects Accomplished Tasks and Stages

\begin{tabular}{ccccc}
\hline & Task & & \multicolumn{2}{c}{ Stage } \\
\cline { 5 - 5 } Humans & Birds & & Humans & Birds \\
\hline 1 & 1 & 2 & 2 \\
2 & 2 & 3 & 3 \\
3 & 3 & 3 & 3 \\
4 & 4 & 4 & 4 \\
5 & 5 & 5 & 5 \\
6 & 9 & 5 & 5 \\
7 & 6 & 5 & 5 \\
8 & 10 & 5 & 6 \\
9 & 11 & 5 & 6 \\
10 & 12 & 6 & 6 \\
11 & 7 & 6 & 5 \\
12 & 8 & 6 & 5 \\
13 & 13 & 6 & 6 \\
14 & 14 & 6 & 6 \\
15 & 15 & 6 & 6 \\
\hline
\end{tabular}

Note- Task order for the birds was determined by averaging the criterion dates (by week) of each group on each task. For human data, see Uzgiris (1987). For the birds, Tasks 9, 7, and 8 were not in human order. However, according to stage development, only Tasks 7 and 8 were out of order. 
the covers, pulling covers just enough to get some seeds, and flying up and landing on the top cover to dislodge it if the plates were too hard to push away. There were no errors on this task.

Task 10. Task 10 was a Stage 6 task, the first of the invisible displacements. Seeds were emptied surreptitiously under a napkin piece so that the subject did not see the seeds in their new location. Sometimes, the conveying instrument was shown to be empty; sometimes, it was placed face down next to the cover. The birds then either went directly to the cover or checked the conveying instrument first. Uzgiris and Hunt regard either reaction as correct. The birds showed that this task was more difficult than a visible displacement by their initial hesitation to react, but this was not over $1 \mathrm{~min}$, and the delay could also have been occasioned by the new procedure as well as by the nature of the displacement. In many sessions, Tasks 9 and 10 were done on the same day.

Tasks 11-13. Tasks 11 and 12 were presented in the same session. Task 11 was apparently more difficult than Task 5 (to which it was similar), with no subjects having fewer mistakes on Task 11 than on Task 5 and 5 subjects having more mistakes. Only 2 subjects had more mistakes on Task 12 than on Task 6, showing that they were past the A-not-B error. Tasks 11 and 12 were finished before the birds were able to successfully perform Task 7 . Eight subjects had fewer sessions on Task 13 than on Task 7 , and only 2 subjects had more mistakes (Table 2).

Tasks 14 and 15 . Tasks 14 and 15 were presented in the same session. The subjects could search under the last screen visited, or they could search under all the screens systematically. These tasks were very difficult because (1) there were several hiding places, (2) the subjects needed to persevere to pull off all the covers, (3) the reward was moved between them, (4) it was not seen deposited, and (5) the action was repeated six times for the two tasks. There were few errors and mistrials. All the birds did systematic searches as well as searches on only the final screen.

\section{Hand-Reared Versus Parent-Reared Subjects}

The hand-raised group was available for testing earlier than was the other group, who could not be removed from the nest box without disrupting the parents who were feeding them. The earlier performance of the handraised group helped to determine earliest age on mastery of a skill, important in a developmental study. By the time both groups passed more difficult tasks $(7,8,12,13,14$, and 15), ages were about the same for both groups. Handrearing seems to have accelerated the performance of the early stage (Stages 2,3 , and 4 ) skills (see Table 4) but not those tasks in Stages 5 and 6, which involved movement of the reward or multiple covers. This result shows the malleability of the young organism. Beginning earlier, the more tractable hand-raised parakeets were able to perform the early tasks at a younger age than were the other birds. On the more difficult tasks, they were not younger, but they met criteria with fewer errors. Biological constraints were possibly important in the delayed eliciting of
Table 4 Average Ages and Ranges of Avian Groups on Stages

\begin{tabular}{cccccc} 
& \multicolumn{2}{c}{ Group 1 } & & \multicolumn{2}{c}{ Group 2 } \\
\cline { 2 - 3 } \cline { 5 - 6 } Stage & Average & Range & & Average & Range \\
\hline 2 & 7 & $7-8$ & & 5 & $4-6$ \\
3 & 9 & $8-10$ & & 8 & $7-8$ \\
4 & 15.5 & $13-18$ & & 10.5 & $9-12$ \\
5 & 21.5 & $17-26$ & & 19 & $13-26$ \\
6 & 23.5 & $19-28$ & & 23 & $17-28$ \\
\hline
\end{tabular}

Note-Average ages and ranges are in weeks.

the later skills that involved perhaps memory or problemsolving skills as well as OP.

The hand-raised birds did achieve scale criteria significantly faster than did the parent-reared birds (MannWhitney $p=.04$ ). The faster performance of Group 2 through the scale was not because they began 1 week earlier but because they made fewer errors (see Table 2). Three of the four fastest times were logged by birds in Group 2. Experiences of being hand-fed and out of the nest box and more accustomed to the investigator seemed to make most Group 2 subjects less distractible in the testing situation, and so they could presumably pay better attention to the tests. Hallock and Worobey (1984) found a human-reared chimpanzee to be more responsive and faster on the testing than a parent-reared chimp.

The pattern of progress through the tests was similar for both avian groups, though a few subjects had less difficulty with Tasks 6 and 7 than most others did. Average age and range of variability of avian subjects according to stage is given in Table 4. There was some age overlap between Stages 5 and 6 in both avian groups. Uzgiris $(1987$, p. 163) noted that there was not much variability among infants at the ages of starting different levels.

\section{Ordinality}

Although the birds differed from human subjects in the ordinal sequence of the tasks performed (Table 3; see also Uzgiris, 1987, p. 146), the order of mastery of tasks was still significantly correlated with human ordinality (Kendall rank correlation coefficient tau $=.83 ; z=4.30$; $p<.00003)$.

Task 9 was the first task that was performed out of order; it involved a hiding procedure at one place instead of a hiding at one of two alternated places (Task 6), so it may have been an easier task for the birds even with unfamiliar and heavier material for covers in Task 9.

Later tasks (the invisible displacements, Tasks 10-15) were apparently not as difficult for the birds as were the earlier tasks with multiple covers (Task 7) and movement of the reward (Task 8). An analysis of the relative success in performance on visible and invisible displacements shows that one third of the total number of sessions in the visible displacements (Tasks 4-9) were sessions with errors, and one fifth of the total number of sessions in the invisible displacements (Tasks 10-15) were sessions with errors (Table 2). Tasks 10,11 , and 12 were simpler tasks in that they involved fewer covers as choices and were 
similar to Tasks 4, 5, and 6, except that the displacements of the reward were done invisibly with an implementing carrier. These later tasks were therefore more familiar in some ways to the subjects than were Tasks 7 and 8 .

\section{Control Test Results}

In the first control test, preferred (safflower seeds) and less preferred (carrot piece) items were shown to the birds and hidden in one of two alternating sites. Most subjects paid attention and recovered seeds in the 3 trials, except for 1 member in each group, who made a hasty search and found the carrot piece (whereupon each ran immediately to the other location for the seeds). They each searched correctly in the other trials, 1 positioning himself in front of the location where he saw the seeds being hidden.

Two tests for olfactory cues. (1) A preferred sunflower seed was placed surreptitiously under one towel piece, and safflower seeds were seen being placed under another towel piece. All birds chose the location where they saw the seeds placed. (2) When seeds were hidden under one of two towels without showing the birds the hidings, the subjects chose correctly one third of the time.

Testing for location versus cover. The reward was placed under one of two blue covers, then a paper plate was placed over that cover, and the latter was removed. The birds proved correct four out of five times, indicating that they did remember the location of the hidden reward and were not simply associating the reward with a particular cover.

In trials presented by the assistant, the results were the same as the usual performance of these birds, showing that they were not simply being cued by the chief investigator.

\section{GENERAL DISCUSSION}

Results from this longitudinal study demonstrated that the young kakarikis did develop full OP, as described by Uzgiris and Hunt (1975). This ability developed gradually in the young birds, as it does in human infants. The avian subjects also did perseverative (A-not-B) searches at a previously rewarded location, as have most other subjects tested (but not dogs and cats). The developmental trajectory of the birds differed from that of human infants in that the early invisible displacements were performed before the later visible displacements with more covers and movement of the reward. The hand-raised group reached criteria significantly faster than did the parent-reared group; individual experiences of the subjects did play a role in that their rearing histories affected task performance.

\section{Ordinality}

The high correlation between human and avian subjects in order of mastering tasks found in the Kendall rank correlation coefficient can be more clearly understood when one notes that, according to stage ordinality (Table 3), there are only 2 tasks (Tasks 7 and 8; Stage 5) that are not in the order human infants have done them. This indicates that while the birds' "stage" advancement was similar to human ordinality, their skill acquisition did not necessarily parallel that of the human subjects tested by Uzgiris and Hunt. Possibly, their delay on Tasks 7 and 8 was because these tasks may involve memory or problem-solving abilities as well as $\mathrm{OP}$.

Moreover, in other studies of human and animal subjects, similar deviations from scale ordinality have been reported. Wood et al. (1980) noted that 2 young chimpanzees and 3 human infants mastered Task 9 before Tasks 7 and 8 . Redshaw (1978) found that 4 infant gorillas and 2 human infants performed Task 9 before Task 8 , and Tasks 10,11 , and 12 were done at the same time (a few weeks after Task 8). In Wise et al. (1974), 2 young rhesus performed Task 10 before Tasks 9 and 7 , and all of these tasks were performed before Task 8. Most human results have followed the $U \& H$ scales ordinality, but there are exceptions. Miller, Cohen, and Hill's (1970) human subjects performed Tasks $9,10,11,12$, and 13 before Task 8. Cornell (1978) also did not find the invisible displacements, relative to the visible displacements, to be more difficult for his human subjects. Furthermore, Uzgiris (1987) noted an "inversion of order" only when 10 of 12 infants achieved a higher task before a lower one (making it less likely to find an inversion). The mixed results raise questions on whether inference (required for invisible displacements) really does have such a delayed development in human and nonhuman animals.

\section{Invisible Displacements}

The birds' early competence on invisible displacements was surprising. Did they learn how to do the tasks through practice on previous visible displacements? Gagnon and Dore $(1992,1993)$ have suggested that "local rule learning" may apply to choices made by subjects who are learning to choose locations. However, this suggestion is not likely to apply to the avian search behaviors. First, the implementing container was not used before Task 10, the first invisible displacement task. There were no errors on Task 10 and few mistrials, suggesting that on this first encounter with an invisible displacement, the birds must have inferred the transfer of the reward, having had no previous opportunity to learn it. Multiple covers were all realigned after the hides so that the subjects would not simply choose the last cover touched by the investigator. Other psittacine birds tested (Pepperberg \& Funk, 1990; Pepperberg \& Kozak, 1986) also have had no errors on Task 10 , and neither did the adult kakariki tested.

Next, the birds' ordinality on the scale suggests that they were not learning to do the tasks in step-by-step fashion. The young birds did not pass Tasks $1-9$ before they were tested on Task 10 . In fact, 3 invisible displacement tasks preceded 2 visible displacement tasks. After the first 2 trajectory tasks and the incompletely covered item of Task 3, the subjects passed only Tasks 4, 5, some of Task 6, and some of Task 9 (an average of 25 trials) before they began (and passed) the 1st session of Task 10 . Each of these tasks differed from the others: number of hiding locations, alternated hiding locations, superimposed covers, an implementing carrier, and hidden trans- 
fer of reward. Finally, as Table 2 indicates, the subjects did not improve consistently through the scale as if they were learning to do the tasks. Later mistakes were still clustered around the tasks involving movement and multiple covers. Many subjects made more mistakes on the later tasks.

\section{Systematic Search}

Every subject systematically searched the screens from last to first on Task 15. More often, they would keep searching around the last screen, crumpling it more or holding it up above the head while looking at it, or they would drag it across the cage floor, calling and looking at the investigator-persistently looking for an expected object. By the end of the testing, they apparently had expectations of what the hidings would yield, and they could also pay close attention in their searching. There were also systematic searches or "follow-up" searches (flying to the hand that had held the reward) by the uncaged parrots tested in Pepperberg and Funk (1990). Accurate hunting and tracking skills are not artificial exercises for many avian species; this is what they do to survive in the wild.

\section{Species Characteristics}

In what ways do the tasks in this scale parallel situations that kakarikis face in the wild? First, these birds recognize and remember objects (many distinct types of food) or features (e.g., cavity nests) in their surroundings in order to locate them again. They monitor objects that drop, and they retrieve them. Upon fledging, young birds follow trajectories of others flying around them or food waving on a branch about them. Insects are a part of the kakariki diet, and the ones they seek are highly cryptic. Minute scale insects and beetle larvae require attentive and persistent searching skills (Greene, 1988). OP ability would encourage persistent search for an insect under or around those leaves where insects had been seen. Invisible displacements may be useful earlier in the developmental trajectory of this species that supplements its diet with insects. This study demonstrates the usefulness of comparing knowledge about a species gained both in the wild and in the laboratory; it supports the continuing relevance of Piagetian theory to help clarify developmental differences across species.

\section{REFERENCES}

Baillargeon, R. (1987). Young infants' reasoning about the physical and spatial characteristics of a hidden object. Cognitive Development, 2, 179-200.

CORNELL, E. H. (1978). Learning to find things: A reinterpretation of object permanence studies. In L. S. Siegel \& C. J. Brainerd (Eds.), $A l$ ternatives to Piaget: Critical essays on theory (pp. 1-10). New York: Academic Press.

Corrigan, R. (1981). Effects of task and practice on search for invisibly displaced objects. Developmental Review, 1, 1-17.

DE BLoIs, S., \& NovaK, M. (1994). Object permanence in rhesus monkeys (Macaca mulatta). Journal of Comparative Psychology, 108, 318-327.

Diamond, A. (1985). Development of the ability to use recall to guide action as indicated by infants' performance on $\mathrm{AB}$ error. Child Development, 56, 868-883.
DORE, F. (1986). Object permanence in adult cats (Felis catus). Journal of Comparative Psychology, 100, 340-347.

DORE, F. (1990). Search behaviour in cats (Felis catus) in an invisible displacement test: Cognition and experience. Canadian Journal of Psychology, 44, 359-370.

Dumas, C. (1992). Object permanence in cats (Felis catus): An ecological approach to the study of invisible displacements. Journal of Comparative Psychology, 106, 404-410.

Dumas, C., \& Brunet, C. (1994). Object permanence in capuchin monkeys: A study of invisible displacements. Canadian Journal of Experimental Psychology, 48, 341-358.

Dumas, C., \& Dore, F. (1989). Cognitive development in kittens (Felis catus): A cross-sectional study of object permanence. Journal of Comparative Psychology, 103, 191-200.

Dumas, C., \& Dore, F. (1991). Cognitive development in kittens (Felis catus): An observational study of object permanence and sensorimotor intelligence. Journal of Comparative Psychology, 105, 357-365.

Dumas, C., \& WILKIE, D. (1995). Object permanence in ring doves. Journal of Comparative Psychology, 109, 143-150.

ETIENNE, A. S. (1973). Searching behavior towards a disappearing prey in the domestic chick as affected by preliminary experience. Animal Behaviour, 21, 749-761.

ETIENNE, A. S. (1984). The meaning of object permanence at different zoological levels. Human Development, 27, 309-320.

Fischer, K., \& BIDELl, T. (1991). Constraining nativist inferences about cognitive capacities. In S. Carey \& R. Gelman (Eds.), Epigenesis of mind (pp. 199-235). Hillsdale, NJ: Erlbaum.

FISCHER, K., \& JENNINGS, S. (1981). Emergence of representation in search. Developmental Review, 1, 18-30.

Fragaszy, D., \& Visal Berghi, E. (1989). Social influences on the acquisition of tool-using behaviors in tufted capuchin monkeys (Cebus apella). Journal of Comparative Psychology, 103, 159-170.

GAGNON, S., \& DORE, F. (1992). Search behavior in various breeds of adult dogs: Object permanence and olfactory cues. Journal of Comparative Psychology, 106, 58-68.

GaGnon, S., \& DoRE, F. (1993). Search behavior of dogs (Canis familiaris) in invisible displacement problems. Animal Learning \& Behavior, 21, 246-254

GaGnon, S., \& Dore, F. (1994). Cross-sectional study of object permanence in domestic puppies (Canis familiaris). Journal of Comparative Psychology, 108, 220-232.

Goulet, S., Dore, F., \& Rousseau, R. (1994). Object permanence and working memory in cats (Felis catus). Journal of Experimental Psychology, 20, 347-365.

GREENE, T. (1988). Behavioural ecology of the red-crowned parakeet and yellow-crowned parakeet on Little Barrier Island. Unpublished master's thesis, University of Auckland.

Gruber, H., Girgus, I., \& Banuazizi, A. (1971). Development of object permanence in the cat. Developmental Psychology, 4, 9-15.

HALLOCK, M., \& Worobey, J. (1984). Cognitive development in chimpanzee infants (Pan troglodytes). Journal of Human Evolution, 13, 441-447.

HARRIS, P. (1983). Infant cognition. In M. Haith \& J. Campos (Eds.), Handbook of child psychology: Infancy and developmental psychology (Vol. 2, pp. 688-782). New York: Wiley.

HEAly, S., \& GUILFORD, T. (1990). Olfactory-bulb size and nocturnality in birds. Evolution, 44, 339-346.

MANDLER, J. (1990). A new perspective on cognitive development in infancy. American Scientist, 78, 236-243.

Mathieu, M., \& Bergeron, G. (1981). Piagetian assessment of cognitive development in chimpanzees (Pan troglodytes). In A. B. Chiarelli \& R. S. Corruccini (Eds.), Primate behavior and sociobiology (pp. 142147). Berlin: Springer-Verlag.

Meltzoff, A., Kuhl, P., \& MoOre, M. (1991). Perception, representation, and the control of action in newborn and young infants. In M. Weiss \& P. Zelago (Eds.), Newborn attention (pp. 377-411). Norwood, NJ: Ablex.

Miller, D., Cohen, L., \& Hill, K. (1970). A methodological investigation of Piaget's theory of object concept development in the sensorymotor period. Journal of Experimental Psychology, 9, 59-85.

Natale, F., \& ANTINUCCI, F. (1989). Stage 6 object concept and repre- 
sentation. In A. Antinucci (Ed.), Cognitive structure and development in nonhuman primates (pp. 97-112). Hillsdale, NJ: Erlbaum.

Nixon, A. (1982). Aspects of the ecology and morphology of Cyanoramphus parakeets and hybrids from Mangere Island, Chatham Islands. Unpublished master's thesis, Victoria University.

PARKER, S. T. (1977). Piaget's sensorimotor series in an infant macaque. In S. Chevalier-Skolnikoff \& F. E. Poirier (Eds.), Primate biosocial development: Biological, social and ecological determinants (pp. 43112). New York: Garland.

Parker, S. T., \& Gibson, K. R. (1977). Object manipulation, tool use and sensorimotor intelligence as feeding adaptations in Cebus monkeys and great apes. Journal of Human Evolution, 6, 623-641.

Pasnak, R., Kurkian, M., \& Triana, E. (1988). Assessment of Stage 6 object permanence. Bulletin of the Psychonomic Society, 26, $368-370$.

PepperberG, I. M., \& Funk, M. S. (1990). Object permanence in four species of psittacine birds: An African Grey parrot (Psittacus erithacus), an Illiger mini macaw (Ara maracana), a parakeet (Melopsittacus undulatus), and a cockatiel (Nymphicus hollandicus). Animal Learning \& Behavior, 18, 97-108.

Pepperberg, I. M., \& Kozak, F. (1986). Object permanence in the African Grey parrot (Psittacus erithacus). Animal Learning \& Be havior, 14, 322-330.

Piaget, J. (1953). Origin of intelligence in the child. London: Routledge \& Kegan Paul.

PIAGET, J. (1954). The construction of reality in the child. New York: Basic Books.

PoTI, P. (1989). Early sensorimotor development in Macaques. In F. Antinucci (Ed.), Cognitive structure and development in nonhuman primates (pp. 39-53). Hillsdale, NJ: Erlbaum.

REDShaW, M. (1978). Cognitive development in human and gorilla infants. Journal of Human Evolution, 7, 133-141.

Schino, G., Spinozzi, G., \& Berlinguer, L. (1990). Object concept and mental representation in Cebus apella and Macaca fascicularis. Primates, 31, 537-544.

SPINOzZI, G., \& NATALE, F. (1989). Early sensorimotor development in gorilla. In F. Antinucci (Ed.), Cognitive structure and development in nonhuman primates (pp. 21-38). Hillsdale, NJ: Erlbaum.
Stettner, L. J., \& Matyniak, K. (1968). The brain of birds. Scientific American, 218, 64-76.

TAYLOR, R. (1985). Status, habits and conservation of Cyanoramphus parakeets in the New Zealand region. In P. J. Moore (Ed.), Conservation of island birds: Case studies for the management of threatened island species (pp. 195-211). Cambridge, U.K.: International Council of Bird Preservation.

TinkLePaUgh, O. T. (1928). An experimental study of representative factors in monkeys. Journal of Comparative Psychology, 8, 197-236.

TinkLePaugh, O. T. (1932). Multiple delayed reaction with chimpanzees and monkeys. Journal of Comparative Psychology, 13, 207-243.

Triana, E., \& Pasnak, R. (1981). Object permanence in cats and dogs. Animal Learning \& Behavior, 9, 135-139.

UzGiris, I. C. (1987). The study of sequential order in cognitive development. In I. C. Uzgiris \& J. M. Hunt (Eds.), Infant performance and experience: New findings with the ordinal scales (pp. 131-167). Urbana: University of Illinois Press.

UzGiRis, I. C., \& Hunt, J. M. (1975). Assessment in infancy: Ordinal scales of psychological development. Urbana: University of Illinois Press.

Vaughter, R. M., Smotherman, W., \& Ordry, J. M. (1972). Development of object permanence in the infant squirrel monkey. Developmental Psychology, 7, 34-38.

Wellman, H., Cross, D., \& Bartsch, K. (1986). Infant search and object permanence: A meta-analysis of the A-not-B error. Monographs of the Society for Research in Child Development, 51(3, Serial No. 214).

Wise, K. L., Wise, L. A., \& Zimmerman, R. R. (1974). Piagetian object permanence in the infant rhesus monkey. Developmental Psychology, $10,429-437$.

Wood, S., Moriarty, K. M., Gardner, B. T., \& Gardner, R. A. (1980). Object permanence in child and chimpanzee. Animal Learning \& Behavior, 8, 3-9.

(Manuscript received June 4, 1994; revision accepted for publication November 29, 1995.) 